\title{
Social services established under the new environment of University Library
}

\author{
Na Lin', a \\ ${ }^{1}$ Jilin Agricultural University, Changchun, Jilin province, China \\ a36670921@qq.com
}

Keywords: Social services, information technology, library and information environment

\begin{abstract}
To adapt the request of the times, innovation and development, it is an important topic to the University Library. As educational levels and expanding the size of school universities, information needs continue to mature, and constantly improve the level of scientific research network technology; readers tend to be more diverse. On basis of the concept of "social service" this article proposes and introduce the necessity and urgency of "social service", and proposes a method library "social service" implemented measures and the implementation process need to pay attention and to guide practice.
\end{abstract}

\section{Introduction}

University Library has a rich collection of resources and professional human resources, and these resources will be open society is the inevitable trend of development of the library. Therefore, how to effectively carry out social University Library Information Service, university libraries and the community should work together to explore the issue [1]. From the 1990s, "Social Service of University Library" has been incorporated into the vision of librarians, did some research, but so far there is no single service model.

"Social service" emphasize that a kind of "community-centric service model," customary analysis of the initiative to provide information and services which may require the user to explicitly based on user request or by individual users.

"Social services" in the socialization can be understood from three aspects: the object of extensive service, professional services, the characteristics of products and services. At the same time it is a dynamic process rather than static. It is not limited to the current classification of customization, push technology, intelligent agent technology, database technology, dynamic web technology, visualization, data mining, and knowledge discovery technology [1].

With the network technology continues to mature, in the digital environment, the traditional library is no longer the sole owner and provider of information resources. In order to effectively meet the growing community of readers to the information needs of the University Library must take the initiative and actively adapt innovative reader services, study the establishment of social reader service mechanism.

\section{The necessity and urgency for social service}

Social service demand of University educational level and size of school. With the progress of society, the development of all walks of life, the deepening of quality education, educational level and school size universities have been expanding. Universities not only within the doctoral schools previously declared doctoral, master number is also increasing [2]. In recent years, the masters increased such as engineering, university teachers, MBA and other professional master's degree. In addition a variety of distance education appears Adult Higher Education and relying on a network of various departments and community-oriented orientation or short-term training and education and increasing. All this makes the University Library service object presents a trend of diversification. Diversification of the urgent need for different levels of users of University Library provide social service platform for them to get the best timely and accurate information. 
It is the request of social service schools continuously scientific research level improvment. In recent years, scientific research various colleges and universities is also growing, the author of 10 well-known online schools in number from 1999 to 2008 was included in EI, SCI papers and other publications to analyze the level of scientific research found that 10 years each university continues promotion, the number of papers to be included in the well-known major journals accumulate growth. The Library of "social service" requirements are also increased dramatically [2].

Further investigation found that the author of many old experts, the old professor since the older database to use less knowledge of the computer's operating less skilled, they prefer our library professionals to provide services for them.

As can be seen in the rising level of scientific research, the demand for social services is also growing strongly.

Social service requirement is to optimize the allocation of resources. At present, although some publishers, online search engine and commercial institutions began to provide users with a wide range of information services, but whether it is in technical equipment, electronic literature, network database, or in human resources, systems integration, cultural heritage aspects [2]. University Library resources are any other types of information and information sector institutions can not match. Carry out in-depth "social service", both these advantages University Library, but also to meet the information needs of users at different levels, to improve the reliability and user satisfaction with the library, optimize the allocation of University Library Resources .

Social services can enhance library status. Carry out social services for the majority of users to solve their practical problems to be solved. We can provide them with professional literature intelligence services. Some libraries even become a member of the staff of the research, their research achievements of social services for the smooth development has laid a good foundation [3]. With the library to provide this service Review rising position in the university libraries increasingly high technological content libraries are also increasing, so to enhance the status of the library. In turn we will suffer further enhance this service after excitation such a virtuous circle, so that it is a win-win.

Social Service Library Services Trends. Socialization of University Library Readers' Service, is to meet the information needs of readers. In modern society, users are no longer satisfied with traditional information services, they hope to grasp on their own development or meaningful information of interest at any time, which requires libraries to provide users meet their personal interests and information needs [3]. University Library Information Resource Center as a university, is necessary to provide users with "social service." Thus, "social service" is the development direction of University Library Information Service. But also it is in line with the purpose of the library: "everything for the reader, to all the readers." With the fast development of computer, network communications and other new technologies, the demand for information resources readers unprecedented urgency, with the new requirements for library services. This situation only through the conduct of social reader service can be effectively changed.

\section{Methods of library for the social services in new environment}

Social services are not equivalent to the daily advisory service, SDI service, it is deeper than their meaning. First, we must understand the different types of user demand for various resources. Generally "social services" include: strengthening the construction of digital resources, user modeling, timely delivery of information resources.

Strengthening of Digital Information Resources. To carry out social service, digital information resources is the foundation. Modern Library Digital Information Resources to strengthen the traditional library collections include: printed documents, microfilm products and audio-visual materials and the progressive realization of the digital conversion process, and stored in the large-capacity, high-density storage devices, using digital Library related data storage and identification technologies, digital text, images, video, audio, grading storage, with automated systems to integrate them organically, establish a comprehensive search engine and online free to read and download any [4]. 
Reader database established. "User Modeling" is also known as build readership database. It is through the establishment and maintenance of parameters characterizing the user's characteristics and objectives, identify the user's beliefs, goals and programs to provide social services [4]. These parameters must be selected to ensure sufficient quantity and for a proper representation or description. These parameters are closely related to directly interact with the socialization of the system.

Learn how the user's specific readers information habits, preferences, background, and other requirements required are: online by directing readers to answer questions to determine the properties of the reader, or the use of network technology to track readers related operations on the attributes readers define.

Timely convey various information resources. Timeliness of information in modern society getting stronger, "social service" requirement timeliness. Modern Library in a timely manner to all kinds of information, especially to collect network information processing, and timely provided to the user [4]. When the use of network technology to update the database or paper holdings should update the latest information supplied to different users.

Due to our own understanding of the actual level of scientific research different colleges of their schools, research developments and research needs, the museum can be combined to make some of these actual user modeling presets, increase user attributes to determine accuracy. The contents of which can be used after the completion of network technology to the user information push.

\section{Libraries "social service" Countermeasures}

Although social services is the development direction of the library can be a great extent to meet customer needs, improve service efficiency of the library, but it is also a complex task. At present, the "social service" is still in the preliminary stages of exploration and development in the library area in order to successfully carry out "social service" to pay attention to the following aspects:

Publicity, allowing users to understand the social service. At the beginning of the service to carry out socialization, since we do not know for social services, and in consideration of security, privacy and other aspects of the process cumbersome, the user may exclude social services at the beginning [5]. This requires us to step up publicity to get the user to trust that allows users to eliminate concerns and consciously accept the "social service", the best propagandists are sent to different departments in the library advocacy and lectures in the library combined.

Strengthen the construction of digital resources, and promote information integration. "Social service" to carry out depends on sound information service to provide support, in addition to buying a large number of electronic resources but also focus on integrated museum data resources. To gradually establish and improve OPAC, ILL, document delivery services and other basic information. Construction features of the database, such as: the university's Dissertation databases. Social service information system currently used by everyone because the database format, the system diversity, giving users total more than inconvenience. If you later can adopt a unified system can facilitate the sharing of resources [5]. Currently, most colleges and universities use the file exchange management system, if Huiwen able to provide subsystems and integrated, then the work is relatively easy and regional standardization.

Choose the best time to carry out community service. Only after the user's information needs are met, only to consider their own social information needs. In addition, as technology, time, energy and other reasons Library impossible to carry out large-scale "social service" all types of libraries according to their actual situation, ready to work, the accumulation of time in conditions of sight conditions permit quasi unit to carry out "social service."

Select the appropriate business training personnel. During "social service", the best staff has a good command of foreign languages, computer skills and a good academic background, the library should be considered from several aspects of personnel selection, training, making them user-oriented "information Navigator." The implementation of "Subject Librarian" system in the time is ripe. 


\section{Notes of the social service in the new environment}

Benefit to the public to participate in the management and supervision of the public service. As the informationization level and the continuous improvement of people's living standard, more and more public demand for public services, more and more high quality requirements, the differences between the national and local public service is becoming more and more sensitive, is no longer merely content with the know how much the government spent on public services, more concerned about the spending which results have been achieved, what life brings to the public job real improvement [6]. From meet the demand of information level, the public service of government performance evaluation, and form a regular public report system, not only for the government to further improve China's public service provide decision-making reference, and can meet the information needs of the public, improve their ability to participate in government management and supervision, will be conducive to the decision-making scientific and democratic, is helpful to improve the government's credibility in the public mind.

Polysemy Processing. In social service work due Polysemy different professional people may expect for the same search terms return different results [6]. If the user does not distinguish attribute retrieval service will certainly be user dissatisfaction. Encounter this problem, system modeling information to determine the user's body using fault-tolerant technology and other methods to resolve questions.

Automatic tracking to respect user. When obtaining user information must respect the user. On the one hand to ensure the security and privacy of their data is not abused, on the other hand to respect the user's choice, if you want to automatically track the user needs to create a dynamic demand model, must be the user's consent, do not perform.

Select the appropriate development tools. Select the appropriate language and database system development aspect. As far as possible in order to avoid capital equipment investment capacity, long development cycle, high cost, complexity of programming and consuming system resources these phenomena.

\section{Summary}

In recent years, the University Library "social service" Although there is a certain degree of development, but there are still some problems in practice. Such as capital, technology, ideas, security and user privacy protection, service feedback, awareness of intellectual property, personnel issues. With the development of information technology and improve the laws and regulations of the library, the University Library will promote social service better and faster development.

\section{References}

[1] Q.Q Li, On several ways library for the social services, Library Work and Research, 2006, vol.3, pp. 83-87.

[2] W.Zh. Liu, Library "social service" model, Library Tribune, 2006, vol.5, pp. 185-189.

[3] T.S. Wang, Social service of University Library, University Library, 2006, vol.2, pp. 62-64.

[4] X.X. Cao, Implementation library social service, library forum, 2008, vol.1, pp.53-55.

[5] Y.P. Ma, On the Construction and Development of University Digital Library, Information Development and Economy, 2006, pp.34-38.

[6] J.W. Zhang, Thinking of University Library Construction and Development of New Period, Cultural and educational forum, 2007, pp.53-57. 